\title{
Production Prediction of Water Drive Gas Reservoir using History Matching
}

\author{
Md Sifat Tanveer ${ }^{1 *}$, Mohammad Shahedul Hossain ${ }^{1}$, A. T. M. Shahidul Huqe Muzemder ${ }^{1}$ \\ ${ }^{I}$ Department of Petroleum \& Mining Engineering, Shahjalal University of Science \& Technology, Sylhet, \\ Bangladesh.
}

*Corresponding Author: Md Sifat Tanveer, Department of Petroleum \& Mining Engineering, Shahjalal University of Science \& Technology, Sylhet, Bangladesh.

\begin{abstract}
The uncertainties attached to the characteristics of the underlying aquifer is one of the main constrains of production prediction from gas reservoirs producing under the support of natural water influx. This study has been conducted with Rashidpur Gas Field located in Bangladesh which has tendencies towards pressure maintenance by natural water influx. The presence of aquifer influx was recognized from the behavior of $P / Z$ vs G_P plot and material balance analysis without water influx. The objectives of this study are to determine the unknown aquifer size and permeability through different history matching techniques and perform production prediction with the best fit aquifer parameters. Three history matching techniques; analytical method, graphical method and history simulation have been carried out varying the aquifer outer-inner ratio and permeability. Fetkovich's Semi Steady Sate water influx model is incorporated with the material balance to calculate the cumulative water influx. The best history matching result is observed for aquifer outer-inner ratio of 5 and permeability of 130 md and estimated recovery is $59 \%$ as predicted with the existing well. Due to the uncertainties in areal continuity of the aquifer, water influx model may require frequent update as more exploration and production data become available
\end{abstract}

Keywords: History matching, aquifer fitting, water influx, material balance, MBAL, PROSPER.

\section{INTRODUCTION}

During exploration and development phase of a field, wells are seldom drills in the aquifer to gain necessary information about the porosity, permeability, thickness and fluid properties. Although the petro physical properties are inferred from what has been observed in reservoir, uncertainty remained about the size of the aquifer itself. It is therefore extremely important to accurately adjust the aquifer parameters during history matching to enable a reliable aquifer model to be built which, in turn, can be used for production predictions [1][2].

According to Galas 2003, the general approach of history matching consists of matching field wide pressure and saturation dependent parameters (gas/oil/water production) and input parameters should be adjusted to improve the match, starting with those parameters with the highest uncertainty [3]. Mattax and Dalton 1990, suggested that aquifer properties appropriate for alternation are aquifer transmissibility and aquifer storage capacity [4].

The upper gas sand of Rashidpur Gas Field is producing from well RP 01 since July, 1994. Initial water to gas ratio (WGR) was varied from 0.02 to $0.50 \mathrm{Stb} / \mathrm{MMScf}$, which has been drastically increased to $2.43 \mathrm{STB} / \mathrm{MMScf}$ until December 2012 [5][6]. The pressure decline plot $\left(\mathrm{P} / \mathrm{Z}\right.$ vs $\left.\mathrm{G}_{\mathrm{P}}\right)$ indicates that field is affected by natural water influx and initial gas in place varies from 0.405 to $0.650 \mathrm{Tcf}$ [7]. As the field is producing from only one Well R-1, very little information is obtained about the areal extent and characteristics of aquifer. The main purpose of history matching techniques applied to this study is to build an aquifer model varying the aquifer outer-inner ratio and permeability that best matches with the historical pressure and production data. Once a satisfactory result is observed, the model is used to predict production and recovery from the field. Throughout the study aquifer porosity is kept same as the reservoir porosity. 


\section{LITERATURE REVIEW}

The material balance equation for volumetric depletion drive gas reservoirs is expressed as

$\frac{\mathrm{P}}{\mathrm{Z}}=\frac{\mathrm{P}_{\mathrm{i}}}{\mathrm{Z}_{\mathrm{i}}}\left(1-\frac{\mathrm{G}_{\mathrm{P}}}{\mathrm{G}}\right)$

Where, $G$ is the gas initially in place, $P_{i}=$ initial reservoir pressure, $G_{P}=$ cumulative gas production in Scf, $\mathrm{P}=$ current reservoir pressure, $\mathrm{Z}_{\mathrm{i}}=$ gas deviation factor at $\mathrm{P}_{\mathrm{i}}$ and $\mathrm{Z}=$ gas deviation factor at $\mathrm{P}$. The main assumption underlying Eq. 1 is that water influx is considered negligible and the plot of $P / Z$ $v s G_{P}$ deviates from the linear relationship in the presence of aquifer influx. The modified material balance incorporating amount of aquifer influx $\mathrm{W}_{\mathrm{e}}$ is expressed as

$\frac{P}{Z}=\frac{\frac{P_{i}}{Z_{i}}\left(1-\frac{G_{P}}{G_{i}}\right)}{\left(1-\frac{W_{e} E_{i}}{G}\right)}$

Where, $\mathrm{W}_{\mathrm{e}} \mathrm{E}_{\mathrm{i}} / \mathrm{G}$ is the portion of hydrocarbon pore volume flooded by aquifer water. Unlike Eq. 1 it is a nonlinear which makes the history matching and production prediction complicated. [1]

According to Havlena and Odeh (1963), material balance can be interpreted as equation of straight line [8]. They expressed the material balance as

$$
\mathrm{F}=\mathrm{G}\left(\mathrm{E}_{\mathrm{g}}+\mathrm{E}_{\mathrm{f}, \mathrm{w}}\right)+\mathrm{W}_{\mathrm{e}} \mathrm{B}_{\mathrm{W}}
$$

Where underground fluid withdrawal, $F=G_{P} B_{g}+W_{P} B_{W}$, Gas expansion, $E_{g}=B_{g}+B_{g i}$, Water and rock expansion, $E_{f, w}=B_{g i} \frac{\left(C_{W} S_{W i}+C_{f}\right)}{1-S_{W i}}$. Combining gas expansion $E_{g}$ and water and rock expansion $E_{f, w}$ as $E_{t}$ and rearranging, Eq. 3 can be expressed as

$\frac{F}{E_{t}}=G_{P}+\frac{W_{e}}{E_{t}}$

The plot of $F / E_{t}$ vs $W_{e} / E_{t}$ should be linear and produce a unit slope if the aquifer is properly characterized and intercept at $\mathrm{W}_{\mathrm{e}} / \mathrm{E}_{\mathrm{t}}=0$ is $\mathrm{F} / \mathrm{E}_{\mathrm{t}}=\mathrm{G}_{\mathrm{p}}$. Deviation from the straight line in the upward or downward direction indicates that the amount of water incorporated with the material balance is too small or two large respectively [9]. Dake (1994) presented an excellent discussion of the strengths and weakness of the material balance equation as a straight line. He characterized performance of the aquifer as active, partial or moderate based on the shape of the plot [10].

Methods of calculating cumulative water influx includes the steady state method, the Hurst modified steady-state method and unsteady-state methods such as those of van Everdingen-Hurst and CarterTracy and Fetkovich's approximate method [11]. Fetkovich's water influx method is much simpler for history matching is based on the productivity index concept that water influx rate is directly proportional to the pressure drop between the average aquifer pressure and the pressure at reservoir aquifer boundary. Based on Fetkovich's method cumulative water influx is expressed as

$\mathrm{W}_{\mathrm{e}}=\frac{\mathrm{W}_{\mathrm{ei}}}{\mathrm{P}_{\mathrm{i}}}\left(\mathrm{P}_{\mathrm{i}}-\mathrm{P}\right)\left(1-\mathrm{e}^{-\mathrm{JP} \mathrm{t} t / \mathrm{W}_{\mathrm{ei}}}\right)$

Where $\mathrm{W}_{\mathrm{ei}}$ is the maximum encroachable water influx, $\mathrm{J}$ is the aquifer productivity index is a function of aquifer geometry. For semi steady flowing condition, $\mathrm{J}$ is expressed for radial aquifers as

$\mathrm{J}=\frac{2 \mathrm{fkh}}{\mu\left(\operatorname{Inr}_{\mathrm{ed}}-\frac{3}{4}\right)}$

Where $\mathrm{f}=$ encroachment angle $/ 360, \mathrm{~h}$ is reservoir thickness, $\mathrm{r}_{\mathrm{ed}}=$ aquifer outer-inner ratio, $\mathrm{k}=$ aquifer permeability [12].

\section{Methodology}

\subsection{Reservoir Model Description}

Initially the material balance analysis is conducted assuming the reservoir as a volumetric depletion drive type reservoir using MBAL, Reservoir Engineering Toolkit of Petroleum Experts [13]. The reservoir model was initiated with pressure, production and PVT data listed in Table 1. 
Table1. Reservoir rock, pressure, production and PVT data [5] [14]

\begin{tabular}{|c|c|c|c|c|c|c|}
\hline Reservoir Parameters & Year & $\begin{array}{l}\text { Res } \\
\text { Pressure } \\
\text { Psig }\end{array}$ & $\begin{array}{l}\text { Cum Gas } \\
\text { Prod Bcf }\end{array}$ & $\begin{array}{c}\text { WGR } \\
\text { Stb/MMScf }\end{array}$ & $\mathrm{Z}$ factor & $\mathrm{Bg}$ \\
\hline \multirow{6}{*}{$\begin{array}{c}\text { Initial Pressure: } 2538 \text { Psig } \\
\text { Temperature: } 113^{\circ} \mathrm{F} \\
\text { Porosity: } 0.25 \\
\text { Connate Water Saturation: } \\
0.3\end{array}$} & Jul-94 & 2538 & - & 0.02 & 0.8493 & 0.00533 \\
\hline & Dec-94 & 2500 & 6.33 & 0.03 & 0.8495 & 0.00540 \\
\hline & Dec-97 & 2350 & 54.44 & 0.05 & 0.8499 & 0.00578 \\
\hline & Dec-99 & 2270 & 86.52 & 0.10 & 0.8503 & 0.00600 \\
\hline & Dec-03 & 2150 & 133.07 & 0.31 & 0.8510 & 0.00631 \\
\hline & Dec-05 & 2094 & 151.58 & 0.58 & 0.8514 & 0.00646 \\
\hline \multirow{4}{*}{$\begin{array}{l}\text { Reservoir Thickness: } \\
270 \mathrm{ft} \\
\text { Reservoir Radius: } 9252 \mathrm{ft}\end{array}$} & Dec-07 & 2049 & 168.41 & 0.90 & 0.8518 & 0.00661 \\
\hline & Dec-09 & 2000 & 183.07 & 1.41 & 0.8522 & 0.00675 \\
\hline & Dec-11 & 1960 & 196.01 & 2.06 & 0.8526 & 0.00688 \\
\hline & Dec-12 & 1950 & 201.89 & 2.43 & 0.8529 & 0.00694 \\
\hline
\end{tabular}

Before performing the history matching, presence of aquifer water influx is confirmed initially with conventional $\frac{P}{Z}$ vs $G_{P}$ plot using reservoir pressure and production data listed in Table 1 . The plot of $\frac{\mathrm{P}}{\mathrm{Z}}$ vs $\mathrm{G}_{\mathrm{P}}$ started to deviate after from straight line after few years of production as shown in Fig. 1. Extrapolating the plot, successive increased in GIIP is observed which varies from 0.405 to 0.650 Tcf. Beside the $\frac{P}{Z}$ vs $G_{P}$ plot, graphical plotting of $\frac{F}{E_{t}}$ vs $G_{P}$ was used to understand the strengths of the aquifer. Fig. 2 is produced ignoring the water influx $W_{e}$ term and plotting the left side of Eq. 4 as a function of cumulative gas production $G_{P}$. According to Dake 1994, the upward shape of the plot indicated that the surrounding water drive is an active water drive [10]. For volumetric depletion type reservoir, the plot would have a straight line parallel to the abscissa-whose ordinate value is the GIIP.

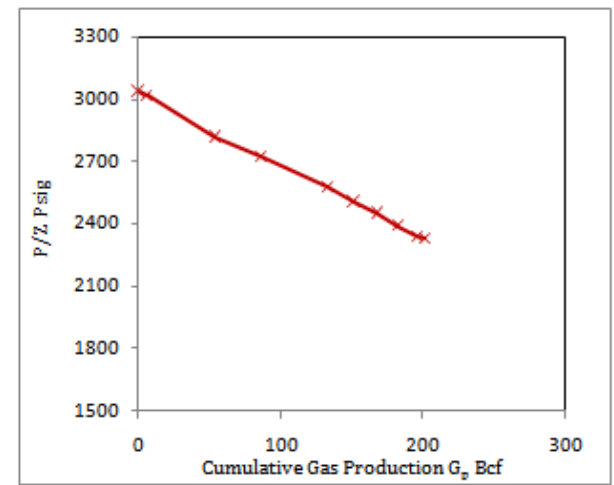

Figure1. Graphical presentation $\frac{\boldsymbol{P}}{\boldsymbol{Z}}$ vs $\boldsymbol{G}_{\boldsymbol{P}}$ plot

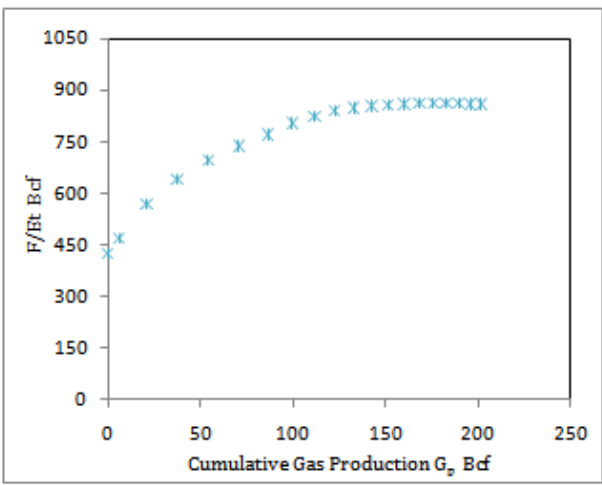

Figure2. Graphical presentation of $\frac{\boldsymbol{F}}{\boldsymbol{E}_{\boldsymbol{t}}}$ vs $\boldsymbol{G}_{\boldsymbol{P}}$ plot

\subsection{History Matching}

In the history matching section of MBAL, Fetkovich's semi steady state radial water influx model is initiated with the aquifer parameters listed in Table 2 and normalized gas-water relative permeability data listed in Table 3. The main purpose of the water influx model is to calculate cumulative water influx. As the size of the underlying aquifer is unknown, three history matching methods; analytical, graphical and history simulation are performed to estimate and adjust the aquifer parameters. Throughout the study aquifer porosity is kept same as the reservoir porosity and permeability for the aquifer is varied from 120 to $160 \mathrm{md}$.

Table2. Input parameters of aquifer properties

\begin{tabular}{|l|l|}
\hline Aquifer outer-inner ratio $\mathrm{r}_{\mathrm{ed}}$ & 4 \\
\hline Aquifer encroachment angle & $180^{\circ}$ \\
\hline Aquifer permeability & 120 \\
\hline
\end{tabular}

Table3. Gas water relative permeability data [5][14]

\begin{tabular}{|c|c|c|}
\hline Sg & Krw & Krg \\
\hline 0.1 & 0.00 & 1.00 \\
\hline 0.2 & 0.00 & 0.70 \\
\hline
\end{tabular}




\begin{tabular}{|c|c|c|}
\hline 0.3 & 0.02 & 0.46 \\
\hline 0.4 & 0.06 & 0.28 \\
\hline 0.5 & 0.14 & 0.15 \\
\hline 0.6 & 0.28 & 0.06 \\
\hline 0.7 & 0.50 & 0.02 \\
\hline 0.8 & 0.81 & 0.00 \\
\hline 0.85 & 1.00 & 0.00 \\
\hline
\end{tabular}

\subsubsection{Analytical Method}

The analytical history matching method of MBAL is a plot based technique which uses non linear regression engine to assist in estimating unknown reservoir and aquifer parameters [13]. The program calculates the production of primary fluid based on the reservoir pressure and production of secondary fluids from the history entered. In this case secondary fluid is water. The program regresses on the $\mathrm{S}_{\mathrm{o}}+\mathrm{S}_{\mathrm{g}}+\mathrm{S}_{\mathrm{w}}=1$ equation. Errors in the material balance from the regression can be checked from the values in standard deviation. $(\mathrm{F}-\mathrm{We}) /\left(\mathrm{G}^{*} \mathrm{E}\right)-1=0$. A value less than 0.1 indicate an acceptable match. To fit an appropriate size aquifer, three different outer-inner radius radios of $r_{e d}=4,5$ and 6 were used in analytical history matching. Based on the seismic and geological evidence it is suspected that the value of $r_{e d}$ is less than 7 .

\subsubsection{Graphical Method}

Once a quality match is observed in the analytical plot, the aquifer size can be confirmed with Havlena and Odeh's water drive plot $\left(F / E_{t}\right.$ vs $W_{e} / E_{t}$ plot) in the graphical method of MBAL [13]. Deviation from the straight line in the upward or downward direction in $F / E_{t} v s W_{e} / E_{t}$ plot indicates that the amount of water incorporated with the material balance is too small or two large respectively. Once the plot took a unit slop shape, the results of cumulative $\mathrm{W}_{\mathrm{e}}$ calculated by the model is assumed appropriate.

\subsubsection{History Simulation}

History simulation of MBAL is used to perform the final quality check on the history matching carried with the graphical and analytical methods. History simulation method does the opposite of analytical method. It calculates reservoir pressures using the historical production data based on the reservoir and aquifer model [13].

\subsection{Well Model and Production Prediction}

Production prediction program of MBAL is run based on the results of history simulation incorporating a well model for different pressure and production constrains. The well model used for this production is produced using PROSPER, production system analysis program of Petroleum Experts [16]. Inflow performance curve (IPR) is generated with multi rate $\mathrm{c}$ and $\mathrm{n}$ method and lift curve (VLP) is generated with Petroleum Experts 2 as shown in Fig. 3 [13].

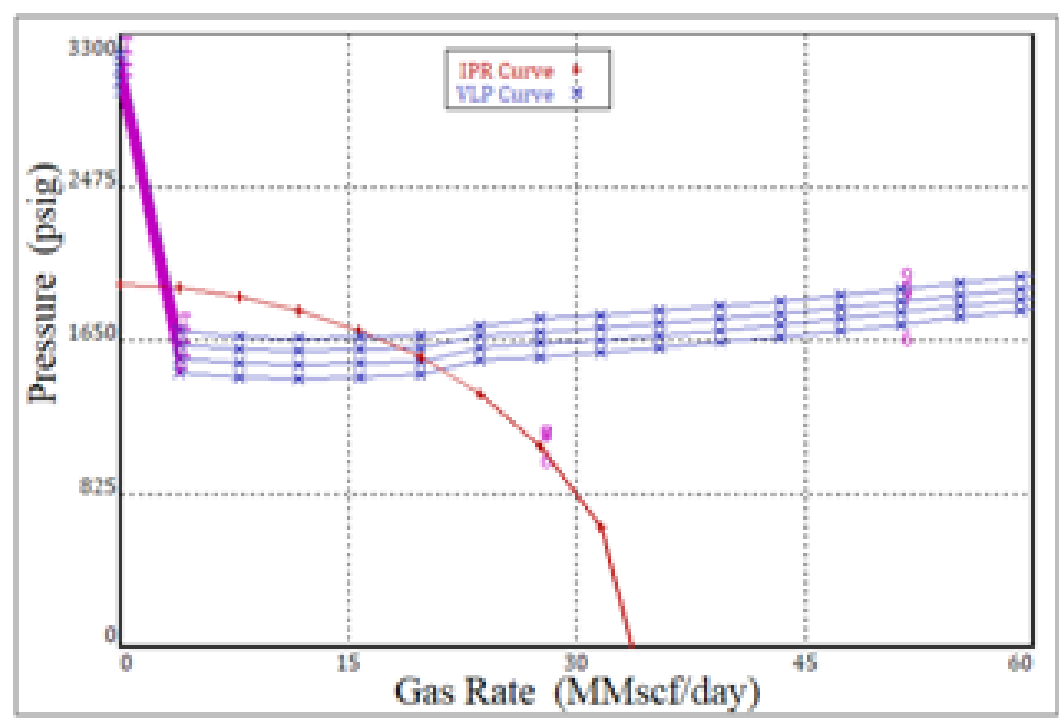

Figure3. Inflow and outflow performance curves 


\section{RESULTS AND DISCUSSION}

\subsection{Results of History Matching}

The results of the analytical method are shown in the Fig. 4 and Table 4. Non linear regression is performed varying aquifer outer-inner ratio, $r_{\text {ed }}$ from 4 to 6 . For $r_{\text {ed }}=4$, calculated gas production is found less than the historical cumulative gas production whereas it was found higher than the historical cumulative gas production for $\mathrm{r}_{\mathrm{ed}}=6$. The calculated gas production best matched with the historical cumulative gas production for $\mathrm{r}_{\mathrm{ed}}=5$ with aquifer permeability of $130 \mathrm{md}$.

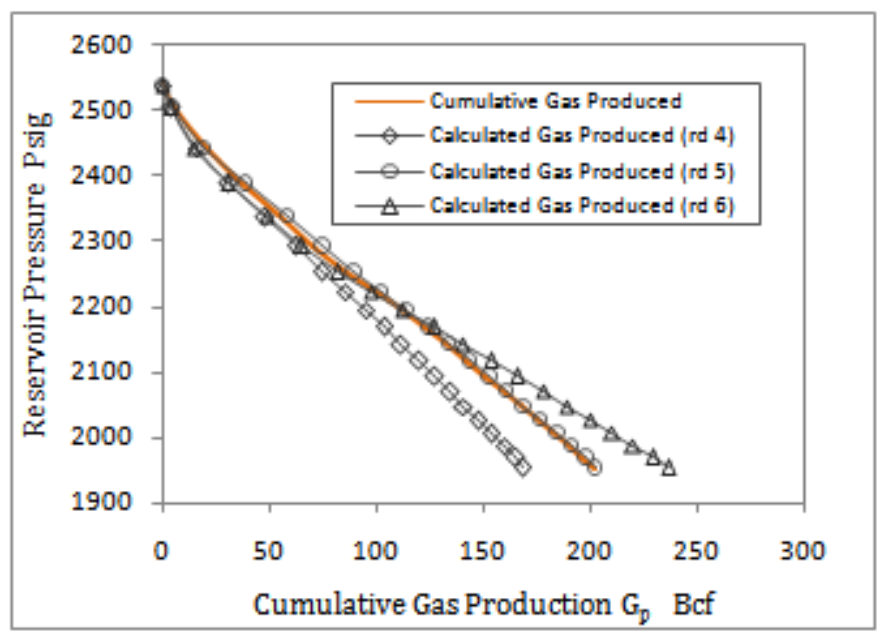

Figure4. History matching results of analytical method

Table4. Estimated aquifer properties from history matching

\begin{tabular}{|l|l|}
\hline $\begin{array}{l}\text { Aquifer outer-inner } \\
\text { radius } \mathrm{r}_{\text {ed }}\end{array}$ & 5 \\
\hline Aquifer permeability & $130 \mathrm{md}$ \\
\hline Aquifer volume & $77252 \mathrm{MMft}^{3}$ \\
\hline
\end{tabular}

The calculated values of cumulative water influx for $r_{\text {ed }}=4,5$ and 6 are graphically represented in Fig. 5 and the results of the graphical method (Havlena and Odeh water drive plot) for those three calculated cumulative water influx are shown is Fig. 6. With $r_{e d}=4$, the $F / E_{t}$ vs $W_{e} / E_{t}$ plot produced an upward shape indicates that the calculated values of cumulative water influx is less than the required. For $r_{e d}=6$, the plot formed a downward shape indicates that the calculated values of cumulative water influx is higher than the required. The best fit result observed for $r_{e d}=5$ and the plot formed straight line with a slop of 45 degree. Extrapolating the straight line at $W_{e} / E_{t}=0$, GIIP is found around $0.425 \mathrm{Tcf}$.

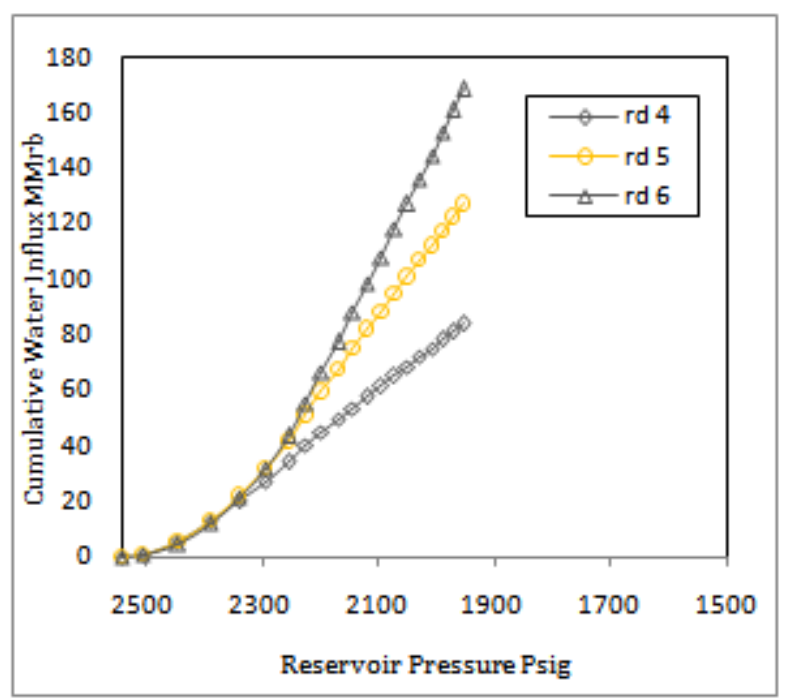

Figure5. Calculated cumulative water influx for $\boldsymbol{r}_{\text {ed }}=4,5$ and 6 


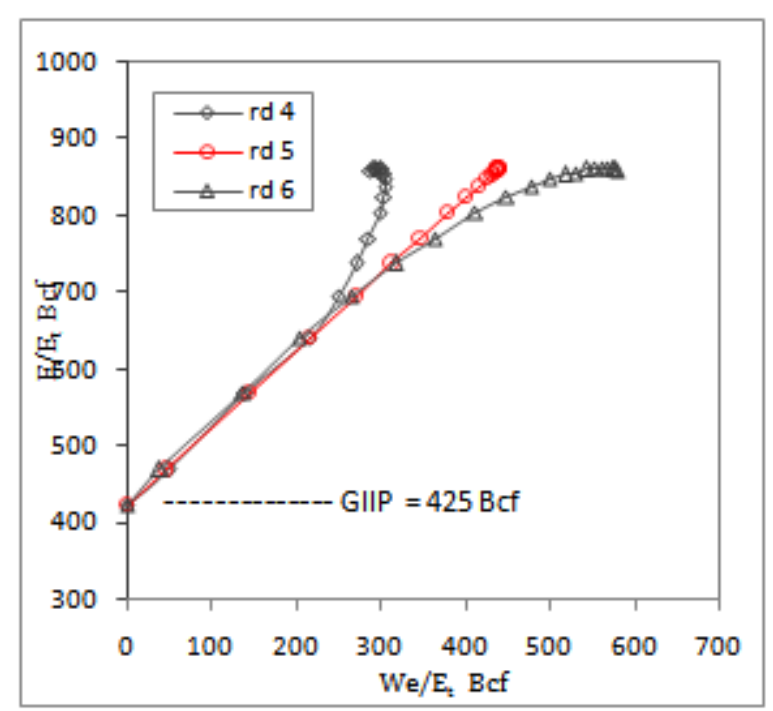

Figure6. Results of graphical method (Havlena and Odeh plot) for $\boldsymbol{r}_{\boldsymbol{e d}}=4,5$

History simulation was performed based on the results of history matching with analytical and graphical methods for aquifer outer-inner ratio $r_{e d}=5$. The reservoir pressure, average gas and water production rates calculated by history simulation best matched with historical pressure and production rates as shown in Fig. 7 and 8.

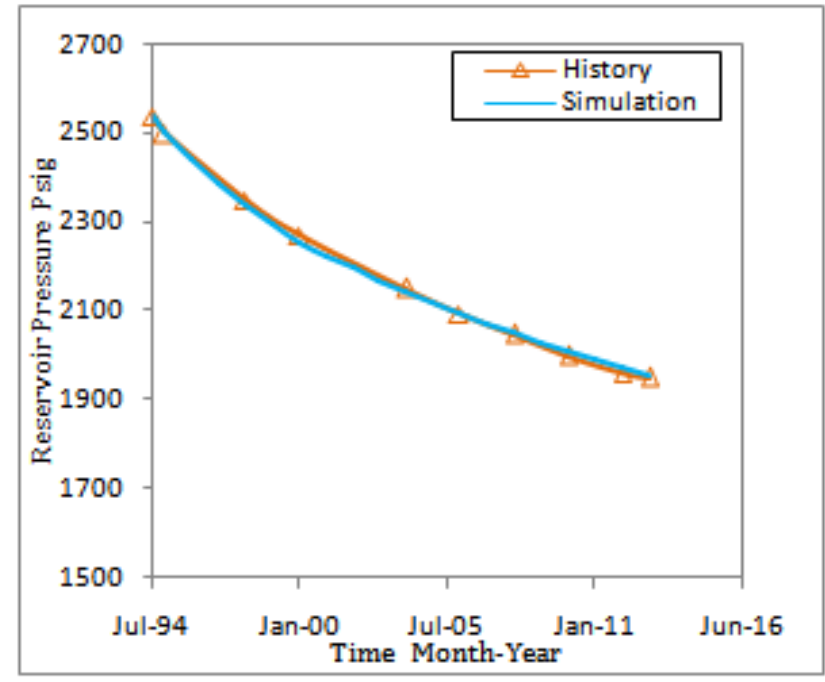

Figure7. Comparison of simulated reservoir pressure with historical pressure

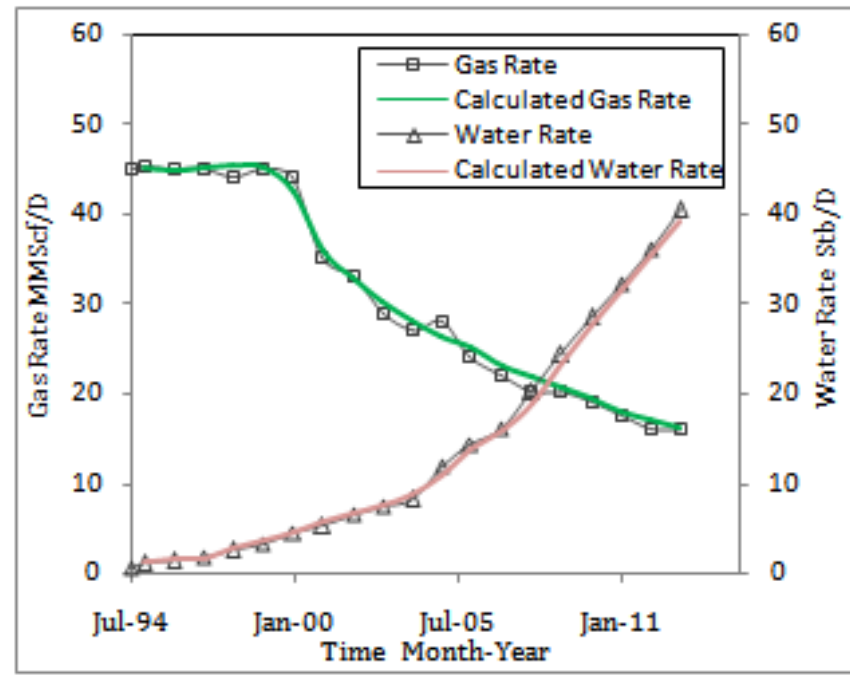

Figure8. Comparison of calculated average production rates with historical production rates 


\subsection{Production Prediction}

Production prediction was run for 18 years with production and abandonment constrains listed in Table 5. The results of reservoir pressure, gas and water production predictions are presented in Fig. 9. With the outflow performance Well R-1, the well can be operated maximum at 16 MMSCFD until November 2022. After that production will have to be reduced successively to maintain the wellhead pressure and water production. The well will be abandoned after February 2026 due to huge water production and $59 \%$ of the reserve can be recovered within this period.

Table5. Production and abandonment and constrains

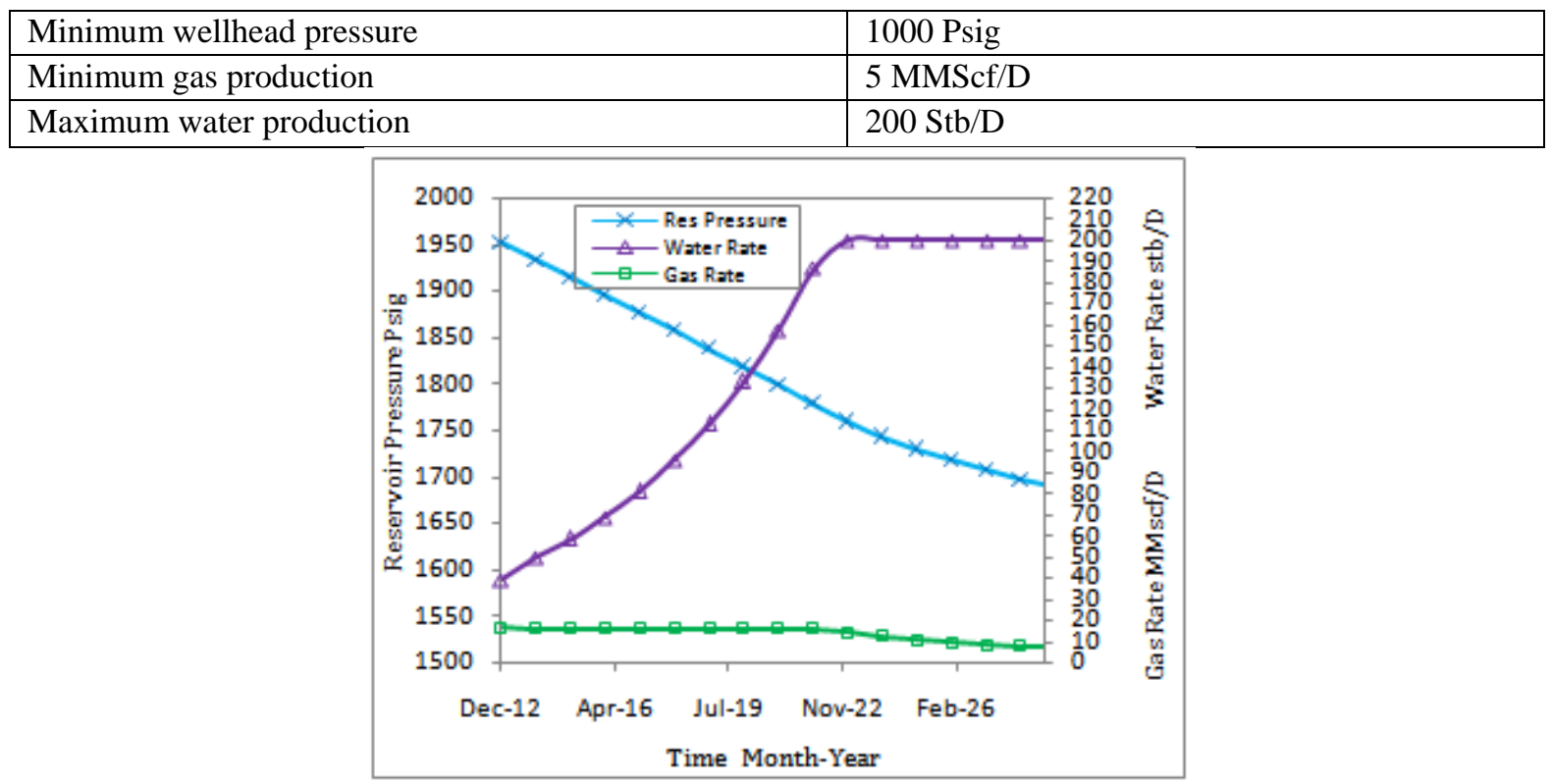

Figure9. Results of production prediction

\section{CONCLUSION}

History matching results of analytical and graphical methods showed that Fetkovitch Semi Steady State water influx model best fits for aquifer outer-inner ratio of $r_{e d}=5$ and aquifer permeability of $130 \mathrm{md}$. Aquifer parameters that have been tuned with the analytical and graphical methods are found accurate from the results of history simulation. A good match is observed in reservoir pressures and average production rates (gas and water) calculated by history simulation with the historical pressure and production data. According to the $\frac{\mathrm{P}}{\mathrm{Z}}$ vs $\mathrm{G}_{\mathrm{P}}$ method, gas initially in place (GIIP) is varied from 0.405 to 0.650 Tcf. From the Havlena and Odeh (water drive) plot, estimated GIIP is found 0.425 Tcf and 59\% of the reserve can be recovered with the existing well. Although recovery can be increased lowering the wellhead pressure but production will have to be ceased due to excessive water production at late times.

\section{REFERENCES}

[1] Dake, L.P., Fundamentals of Reservoir Engineering, Elsevier Science. 1978, ch. 1, pp. 29-32, ch. 9, pp. 303-325.

[2] Craft, B.C. and Hawkins, M., Revised by Terry, R.E., Applied Petroleum Reservoir Engineering, Second Edition, Prentice Hall, 1990, ch. 8, pp. 273-334, ch. 10, pp. 391-424.

[3] Galas, C.M.F., The Art of History Matching-Modelling Water Production under Primary Recovery". Paper PETSOC 2003-21, International Petroleum Conference, SPE, Canada, (2003).

[4] Mattax, C. C. and Dalton R. L., Reservoir Simulation, Richardson, Texas: Monograph Series, SPE, (1990).

[5] Intercomp Kanata Management, Gas Field Appraisal Project, Reservoir Engineering Report, Rashidpur Gas Field, prepared for Canadian International Development Agency (CIDA) and Bangladesh Oil, Gas and Minerals Corporation (Petrobangla), (March 1991).

[6] Beicip Franlab-RSC/Petrobangla, Interim Report on Hydrocarbon Resources for Enhanced Reservoir (ASSET) Management, Petrobangla, (2000).

[7] HCU/NPD, Bangladesh Petroleum Potential and Resource Assessment. Ministry of energy and Mineral Resources, GOB (2001). 
[8] Havlena, D. and Odeh, A.S., The Material Balance as an Equation of a Straight Line, J. Pet. Techn., August: 896-900, Trans. AIME, (1963).

[9] Havlena, D. and Odeh, A.S., The Material Balance as an Equation of a Straight Line Part II, Field Cases. J. Pet. Tech., July: 815-822. Trans. AIME, (1964).

[10] Dake, L., The Practice of Reservoir Engineering, $2^{\text {nd }}$ ed. Amsterdam: Elsevier, (1994).

[11] Ahmed, T., Reservoir Engineering Handbook, $3^{\text {rd }}$ ed. Oxford, UK. Elsevier, (2006).

[12] Fetkovitch, M.J., A Simplified Approach to Water Influx Calculations-Finite Aquifer Systems, J. Pet.Tech., July: 814-828, Trans. AIME, (1971).

[13] IPM 7.50, MBAL, Reservoir Engineering Toolkit, Version 10.5, User Manual, Petroleum Expert, UK (2010). www.petex.com.

[14] Al Mansoori Wireline Services, Pressure Transient Analysis Report, R-1, Sylhet Gas Field Limited, (2007).

[15] Alam, M.S., Gas in Place Estimate of the Habiganj Gas Field Using Material Balance, M. Sc. Thesis, Petroleum and Mineral Resources Engineering Department, BUET, Dhaka (May 2002).

[16] IPM 7.50, PROSPER System Analysis Program, Version 11.5, User Manual, Petroleum Expert, UK (January 2010). www.petex.com.

[17] Agarwal, R. G., Al-Hussainy, R., and Ramey, H. J., The Importance of Water Influx on Gas Reservoirs, J. Pet.Tech., (November 1965).

[18] Bruns, J.R., Fetkovitch, M.J. and Meitzen, V.C., The Effect of Water Influx on p/Z-Cumulative Gas Production Curves. J. Pet. Tech., (March: 1965).

[19] Firoozabadi, A., Olsen, G., \& van Golf-Racht, T., Residual Gas Saturation in Water-Drive Gas Reservoirs, SPE California Regional Meeting, Ventura, California, (8-10 April, 1987).

[20] Katz, D. L., Tek, M. R., and Jones, S. C., A Generalized Model for Predicting the Performance of Gas Reservoirs Subject to Water Drive, SPE Annual Meeting, Los Angeles, (7-10 October, 1962).

[21] Morell E., History Matching of the Norne Field, M.Sc. Thesis, Department for Petroleum Engineering and Applied Geophysics, NTNU, Norway (September 2010).

[22] Odinukwe, J. and Correia, C., History Matching and Uncertainty Assesment of the Norne Field E-Segment Using Petrel RE., M.Sc. Thesis, Department for Petroleum Engineering and Applied Geophysics, NTNU, Norway (June 2010).

Citation: Md Sifat Tanveer, et.al, (2019). "Production Prediction of Water Drive Gas Reservoir using History Matching”, International Journal of Petroleum and Petrochemical Engineering (IJPPE), 5(4), pp.23-30, DOI: http://dx.doi.org/10.20431/2454-7980.0504004

Copyright: () 2019 Authors. This is an open-access article distributed under the terms of the Creative Commons Attribution License, which permits unrestricted use, distribution, and reproduction in any medium, provided the original author and source are credited 